\title{
Trypanosoma cruzi Infection Induces Cellular Stress Response and Senescence-Like Phenotype in Murine Fibroblasts
}

\begin{abstract}
Kamila Guimarães-Pinto ${ }^{1,2}$, Danielle Oliveira Nascimento ${ }^{1}$, Antonia Corrêa-Ferreira ${ }^{1,2}$, Alexandre Morrot ${ }^{3,4}$, Celio G. Freire-de-Lima', Marcela F. Lopes' ${ }^{1}$, George A. DosReis ${ }^{1,5}$ and Alessandra A. Filardy ${ }^{1,2 *}$

IInstituto de Biofísica Carlos Chagas Filho, Universidade Federal do Rio de Janeiro, Rio de Janeiro, Brazil, ${ }^{2}$ Departamento de Imunologia, Instituto de Microbiologia Paulo de Góes, Universidade Federal do Rio de Janeiro, Rio de Janeiro, Brazil, ${ }^{3}$ Faculdade de Medicina, Universidade Federal do Rio de Janeiro, Rio de Janeiro, Brazil, ${ }^{4}$ Laboratório de Imunoparasitologia, Instituto Oswaldo Cruz, Fundação Oswaldo Cruz, Rio de Janeiro, Brazil, 5 Instituto Nacional para Pesquisa Translacional em Saúde e Ambiente na Região Amazônica, Conselho Nacional de Desenvolvimento Científico e Tecnológico, Rio de Janeiro, Brazil
\end{abstract}

OPEN ACCESS

Edited by: Christoph Hölscher, Forschungszentrum Borstel (LG), Germany

Reviewed by: Carlos Robello, Institut Pasteur de Montevideo, Uruguay Uwe Müller, Leipzig University, Germany

${ }^{*}$ Correspondence: Alessandra A. Filardy filardy@micro.ufrj.br

Specialty section: This article was submitted to Microbial Immunology, a section of the journal

Frontiers in Immunology

Received: 07 March 2018 Accepted: 25 June 2018 Published: 09 July 2018

Citation: Guimarães-Pinto K, Nascimento DO, Corrêa-Ferreira A, Morrot A,

Freire-de-Lima CG, Lopes MF, DosReis GA and Filardy AA (2018)

Trypanosoma cruzi Infection Induces Cellular Stress Response and Senescence-Like Phenotype in Murine Fibroblasts.

Front. Immunol. 9:1569. doi: 10.3389/fimmu.2018.01569
Trypanosoma cruzi infects and replicates within a wide variety of immune and nonimmune cells. Here, we investigated early cellular responses induced in NIH-3T3 fibroblasts upon infection with trypomastigote forms of T. cruzi. We show that fibroblasts were susceptible to T. cruzi infection and started to release trypomastigotes to the culture medium after 4 days of infection. Also, we found that $T$. cruzi infection reduced the number of fibroblasts in 3-day cell cultures, by altering fibroblast proliferation. Infected fibroblasts displayed distinctive phenotypic alterations, including enlarged and flattened morphology with a nuclei accumulation of senescence-associated heterochromatin foci. In addition, infection induced an overexpression of the enzyme senescence-associated $\beta$-galactosidase (SA- $\beta$-gal), an activation marker of the cellular senescence program, as well as the production of cytokines and chemokines involved with the senescenceassociated secretory phenotype (SASP) such as IL-6, TNF- $\alpha$, IL-1 $\beta$, and MCP-1. Infected fibroblasts released increased amounts of stress-associated factors nitric oxide (NO) and reactive oxygen species (ROS), and the treatment with antioxidants deferoxamine (DFO) and $N$-acetylcysteine reduced ROS generation, secretion of SASP-related cytokine IL-6, SA- $\beta$-gal activity, and parasite load by infected fibroblasts. Taken together, our data suggest that $T$. cruzi infection triggers a rapid cellular stress response followed by induction of a senescent-like phenotype in $\mathrm{NIH}-3 \mathrm{~T} 3$ fibroblasts, enabling them to act as reservoirs of parasites during the early stages of the Chagas disease.

Keywords: Chagas disease, Trypanosoma cruzi, senescent-like, senescence-associated $\beta$-galactosidase, senescence-associated secretory phenotype, reactive oxygen species, deferoxamine

\section{INTRODUCTION}

The intracellular protozoan parasite Trypanosoma cruzi is the etiological agent of Chagas disease, the main endemic parasitic disease of Latin America, and a public health issue in non-endemic regions, including USA (1-3). Natural route of infection occurs when a triatomine insect vector deposit infective metacyclic trypomastigotes with its feces on the host's skin during blood meal. The 
parasites penetrate the skin and dermis by small lesions caused by wound scratching $(4,5)$. Trypomastigotes invade immune and non-immune host cells, where they are converted into the replicative amastigote form. After several rounds of replication, amastigotes differentiate into highly motile infective trypomastigotes that are released in the intercellular spaces to disseminate the infection to other cells $(6,7)$. The early parasite interactions with host cells may determine the outcome of T. cruzi infection. However, most of the studies are focused on macrophages and cardiomyocytes, since they are responsible for triggering immune responses and cardiac lesions in Chagas disease, respectively $(8,9)$. Nonetheless, before the parasites gain access to these cell types, they need to interact/invade epithelial cells and fibroblasts that compose epithelial/mucous barriers to insure dissemination and the establishment of chronic infection (10-12). Particularly, T. cruzi has the ability to non-selectively infect a wide range of cell types, which is probably due to its ability to simultaneously express several surface glycoproteins, and interact with several mammalian receptors, including toll-like receptors, TGF- and EGF-receptors, and tyrosine kinases receptors; both factors are required for optimal parasite adhesion, penetration, and transit through host cell parasitophorous vacuoles in order to establish an intracellular infection $(8,11,13,14)$. Several in vitro studies have shown that trypomastigotes infect epithelial cells and fibroblasts $(6,11,15-17)$; and an interesting histopathological investigation, that analyzed placentas from mothers who gave birth to babies congenitally infected with T. cruzi, has shown parasites in fibroblasts and macrophages of chorion, membranes, and chorionic plate, mainly in the area of membrane insertion (18).

Trypanosoma cruzi employs a number of strategies to evade the immune responses and prevail itself in the infected hosts. Regulating host cell cycle is one of the mechanisms used by many intracellular pathogens, including T. cruzi, to facilitate its replication and perpetuity within the organism (19-22). It has been shown that resistance and susceptibility to T. cruzi infection is cyclic and varies accordingly to cell cycle phase (23). In addition, it was reported that T. cruzi infection impedes cell cycle progression (22), and induces an upregulation of several genes involved in cell cycle control, suppressing proliferation in the host non-immune cells (11).

Suppression of cell proliferation is the most prominent feature of cellular senescence, a complex stress response, in which senescent cells undergo broad morphological and phenotypic changes (24). Senescent cells display increased cell size and flat morphology with a nuclei accumulation of senescence-associated heterochromatin foci (SAHF) $(25,26)$. Besides that, senescent cells are characterized by increased secretion of many factors including senescence-associated $\beta$-galactosidase (SA- $\beta$-gal) $(27,28)$, as well as proinflammatory cytokines/chemokines, and NO, which characterize senescence-associated secretory phenotype (SASP) $(29,30)$. SASP cytokines/chemokines include IL-6, TNF- $\alpha$, IL-1 $\beta$, and MCP-1 $(30,31)$, which have effects in the tissue microenvironment, propagating the stress response and communicating with neighboring cells. Cellular senescence has been associated with the process of aging (32), during embryogenesis (33), and diseases such as cancer $(34,35)$ and infectious diseases (36-39). Particularly, it has been already described that chronic immune activation during Chagas disease results in $\mathrm{CD}^{+}$and $\mathrm{CD}^{+} \mathrm{T}$ cells immune senescence due to cell exhaustion by the T. cruzi persistence in the host $(40,41)$. In addition, cardiomyocytes infected with $T$. cruzi have enhanced reactive oxygen species (ROS) production, which leads to DNA damage (42). However, whether DNA damage induces senescence in Chagas disease or even whether senescence is induced in other non-immune cell types during the acute phase of infection remains to be addressed.

Here, we investigated early cellular responses to T. cruzi infection that may be relevant to the establishment of chronic disease by using the murine fibroblast cell NIH-3T3. We found that T. cruzi infection reduced fibroblasts proliferation and altered their morphology to enlarged and flattened cells, and promoted nuclei accumulation of SAHF. Concomitantly, infected fibroblasts had increased SA- $\beta$-gal activity, and production of cytokines involved with SASP such as IL-6, TNF- $\alpha$, and IL-1 $\beta$, as well as the chemokine MCP-1. In addition, we observed that T. cruziinfected fibroblasts released increased levels of NO and ROS, and the addition of antioxidants DFO and $N$-acetylcysteine (NAC) reduced ROS generation, decreased the secretion of SASP-related cytokine IL- 6 , and SA- $\beta$-gal activity, and reduced the parasite load by infected fibroblasts. Taken together, our findings suggest that $T$. cruzi infection triggers a rapid cellular stress response in NIH-3T3 fibroblasts, culminating in an induction of a senescentlike phenotype that enables these cells to act as reservoirs of parasites, during the early stages of the Chagas disease.

\section{MATERIALS AND METHODS}

\section{Mammalian Cell Culture and Parasites}

Murine NIH-3T3 fibroblasts (Instituto Nacional de Controle de Qualidade em Saúde; Fiocruz, Brazil) were maintained in Dulbecco's modified Eagle's medium (Gibco) supplemented with $2 \mathrm{mM}$ glutamine, $5 \times 10^{-5} \mathrm{M} 2$-Mercaptoethanol $(2-\mathrm{ME}), 10 \mu \mathrm{g} / \mathrm{mL}$ gentamicin, $1 \mathrm{mM}$ sodium pyruvate, and $0.1 \mathrm{mM}$ MEM nonessential amino acids plus 10\% fetal bovine serum (FBS) (all from Gibco) at $37^{\circ} \mathrm{C}$ in a $5 \% \mathrm{CO}_{2}$ atmosphere. Tissue culture-derived T. cruzi trypomastigotes (Dm $28 \mathrm{c}$ strain) were obtained from the supernatant of infected LLC-MK2 (Rhesus monkey kidney epithelial cells; ATCC, Manassas, VA, USA), 5-9 days post-infection (p.i.) by weekly passages (43). All experiments were performed under biosafety level 2.

\section{Fibroblast Infection and Parasite Load}

NIH-3T3 fibroblasts monolayers $\left(5 \times 10^{4}\right.$ cells/well in 24-well plates) were seeded and after $2 \mathrm{~h}$, adherent cells were infected with tissue culture-derived T. cruzi trypomastigotes at a 5:1 parasite/cell ratio in $0.5 \mathrm{~mL}$ of supplemented DMEM plus $2.5 \%$ FBS at $37^{\circ} \mathrm{C}$ in a $5 \% \mathrm{CO}_{2}$ atmosphere, overnight. In the following day, monolayers were extensively washed to remove extracellular parasites and supplemented DMEM plus 2.5\% FBS was added. In some experiments, the antioxidants NAC (20 mM; Sigma) or DFO ( $40 \mu \mathrm{M}$; Sigma) were diluted in sterile water and added or not to the cell cultures right after infection and washing step. After 72 h p.i., culture supernatants were collected for analysis and adherent NIH-3T3 cells were detached by treatment with 
phosphate buffer saline (PBS) containing 2 mM EDTA and 2\% FBS, washed, and resuspended in supplemented DMEM plus $2.5 \%$ FBS. In some experiments, supernatants from either uninfected or infected NIH-3T3 were collected after 3 days of incubation, frozen and $50 \%$ of them were used with $50 \%$ of fresh medium to have a conditioned medium (CM) of T. cruzi-infected (Tc-CM) or non-infected (Ctrl-CM) conditions. The cellular numbers and viability were evaluated by the differential counting using Trypan blue solution (Sigma-Aldrich; 1:2). For assessment of parasite load, viable parasites, assessed as motile extracellular trypomastigotes released in culture supernatants, were counted in a Neubauer chamber.

\section{Proliferation Assay}

To determine the proliferation of NIH-3T3 cells, carboxyfluorsecein diacetate succinimidyl ester (CFSE) staining was performed. NIH-3T3 cells $\left(1 \times 10^{5}\right)$ were seeded in $75 \mathrm{~cm}^{2}$ culture flasks and after 5-7 days, cells were harvested by trypsinization and labeled with $5 \mu \mathrm{M}$ CFSE (Molecular Probes, EUA) in PBS at $37^{\circ} \mathrm{C}$ for $20 \mathrm{~min}$. Labeled cells were washed and seeded $\left(5 \times 10^{5}\right.$ in six-well plates) with supplemented DMEM plus 2.5\% FBS and left for adherence for $2 \mathrm{~h}$. After this time, fresh culture medium containing tissue culture-derived T. cruzi trypomastigotes was added to the cells and cultured for $72 \mathrm{~h}$ at $37^{\circ} \mathrm{C}$ in a $5 \% \mathrm{CO}_{2}$ atmosphere. After 72 h p.i., adherent NIH-3T3 cells were detached by treatment with PBS containing $2 \mathrm{mM}$ EDTA and $2 \%$ FBS, washed and resuspended with FACS buffer (PBS containing 3\% FBS and $0.02 \%$ sodium azide). Proliferation was evaluated using a FACSCalibur flow cytometer (BD). Fluorescence was compared with a T0 time point corresponding to cells incubated with CFSE and immediately analyzed. For analysis, Flow Jo software was used (TreeStar). To evaluate the relative frequency of proliferating (CFSE low) and non-proliferating (CFSE high) fibroblasts, we first gated the cells based on FSC-A versus SSC-A parameters.

\section{$\beta$-Galactosidase Assay}

Senescence-associated $\beta$-galactosidase activity detectable at $\mathrm{pH}$ 6.0 was assayed according to Lee et al. (28). Briefly, equal numbers of cells were collected, washed, and resuspended in phosphate buffer ( $\mathrm{pH}$ 6.0). Cells were lysed by freeze/thaw, and the lysates were centrifuged at $12,000 \mathrm{~g}$ for $7 \mathrm{~min}$. The supernatants were mixed with 2-nitrophenyl- $\beta$-D-galactopyranoside (ONPG) (Sigma) $(2.2 \mu \mathrm{g} / \mu \mathrm{L})$ in $1 \mathrm{mM} \mathrm{MgCl}{ }_{2}$ buffer. After incubation at $37^{\circ} \mathrm{C}$ for $12 \mathrm{~h}, 50 \mu \mathrm{L}$ of $1 \mathrm{M}$ sodium carbonate were added, and absorbance at $410 \mathrm{~nm}$ was measured in a plate spectrophotometer (SpectraMax M5 microplate reader).

\section{Cytokine Measurement}

Supernatants from either uninfected or infected NIH-3T3, treated or not with NAC or DFO, were collected after 3 days of incubation and assayed for IL- 6 , IL- $1 \beta$, TNF- $\alpha$, MCP- 1 , and IL-10 cytokines by the sandwich immunoassay (ELISA), as recommended by the manufacturer (R\&D Systems or eBioscience). The optical density was determined in a plate spectrophotometer (SpectraMax M5 microplate reader). The concentrations of cytokines were calculated from a standard curve of recombinant cytokines. Results are mean and SE of triplicate cultures.

\section{Nitric Oxide}

Production of NO was assayed indirectly by quantification of nitrites accumulated in the supernatant of cultures by using the Griess colorimetric method described by Kwon et al. (44).

\section{Reactive Oxygen Species}

Intracellular levels of ROS were measured by oxidation of nonfluorescent $2^{\prime}, 7^{\prime}$ dichlorofluorescin probe, delivered as diacetate form (DCFH-DA), to the fluorescent product $2^{\prime}, 7^{\prime}$ dichlorofluorescein (45). NIH-3T3 fibroblasts were plated in 96-well black plates and loaded for $20 \mathrm{~min}$ at $37^{\circ} \mathrm{C}$ with $10 \mu \mathrm{M}$ DCFH-DA (Sigma-Aldrich). After the washing step with Hanks' Balanced Salt Solution without phenol red (Gibco), fibroblasts were infected with tissue culture-derived T. cruzi trypomastigotes and treated or not with NAC or DFO, overnight. In the following day, monolayers were washed to remove extracellular parasites, fresh supplemented DMEM plus 2.5\% FBS were added with or without the antioxidants NAC or DFO, for additional 3 days. Fluorescence was measured (529 nm excitation; $504 \mathrm{~nm}$ emission) from 2 to $72 \mathrm{~h}$ p.i. in a spectrophotometer (SpectraMax M5 microplate reader).

\section{Statistical Analyses}

All statistical analyses were performed using Prism 6.0 software (GraphPad Software, La Jolla, CA, USA). All experiments shown are representative of at least two independent experiments with similar results. Normal distribution of data was determined using Kolmogorov-Smirnov test. Data with normal distributions were evaluated by unpaired Student's two-tailed $t$-test. For the data that were not normally distributed, the non-parametric MannWhitney test was employed. For cells counting and parasite load analyses, data were log-transformed before statistical analyses. Data are expressed as the mean of technical replicates per treatment and SE. Differences with a $p$ value $<0.05$ were considered significant.

\section{RESULTS}

\section{T. cruzi Infection Decreases the Number of NIH-3T3 Fibroblasts In Vitro}

To investigate the initial events of T. cruzi infection, NIH-3T3 fibroblasts were infected and as expected, they released trypomastigotes into culture supernatants at day 4 . At the day 6 , we found the average of $10^{5}$ trypomastigotes released by each fibroblast (Figure 1A). We also observed an increasing of amastigote forms in the supernatants, which reflects a spontaneous differentiation of trypomastigotes to amastigotes, as previously described $(46,47)$. We next evaluated the effects of $T$. cruzi infection in NIH-3T3 fibroblasts by infecting these cells with culture-derived trypomastigotes overnight followed by a washing step to eliminate extracellular parasites. After 3 days p.i., cells were recovered from the plates and counted in the optical microscope. We found a remarkable reduction of the overall cell numbers in the infected compared to non-infected condition (Figure 1B, upper panel and Figure 1C). To investigate whether the reduced cell numbers in the infected condition were due to cell death, we further evaluated 

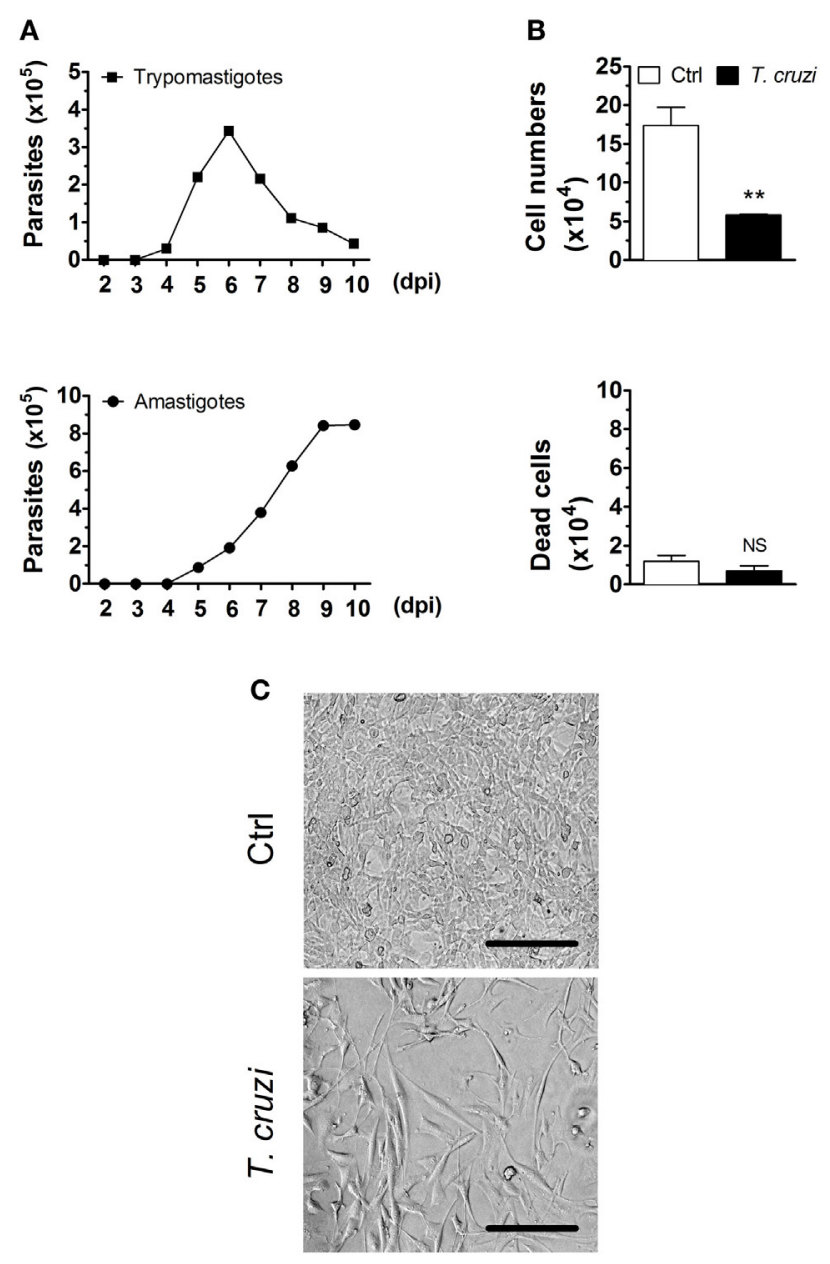

FIGURE 1 | Trypanosoma cruzi infection decreases the number of fibroblasts in culture. NIH-3T3 fibroblasts were infected with culture-derived trypomastigotes of T. cruzi (MOI 5:1). (A) Assessment of extracellular parasitic load (trypomastigote and amastigote forms) in culture supernatants over 10 days of infection. (B) Quantification of the number of T. cruzi-infected or non-infected fibroblasts after 3 days post-infection in the optical microscope. Dead cells were evaluated by Trypan blue exclusion assay. (C) Photographs are representative of six randomly chosen fields and denote a confluent cell culture in the absence but not in the presence of T. cruzi infection (20x magnification). Scale bars are equal to $50 \mu \mathrm{m}$. Data are presented as the mean \pm SE of three biological replicates. Data were log-transformed and analyzed by unpaired, two-tailed Student's $t$-test. ${ }^{* *} p<0.01$; NS, not significant, $p>0.05$. Data are representative of at least three independent experiments with similar results. Abbreviations: $\mathrm{MOI}$, multiplicity of infection; dpi, days post-infection; Ctrl, control.

the numbers of dead cells by Trypan blue exclusion assay, and we observed equal numbers of dead cells in the infected and noninfected conditions (Figure 1B, lower panel and Figure 1C). By annexin $\mathrm{V}$ and 7AAD staining, we found that most of dead cells were apoptotic (data not shown). In addition, we observed equal numbers of detached cells in the supernatants in both conditions (data not shown). Infected fibroblasts displayed distinctive phenotypic alterations, including enlarged and flattened morphology (Figure 1C). Together, our data suggest that NIH-3T3 fibroblasts are not able to control the initial parasite replication, acting as a reservoir of $T$. cruzi at the early stages of infection; and that T. cruzi infection may interfere with the cellular proliferative capacity of fibroblasts.

\section{T. cruzi Infection Inhibits the Proliferation of NIH-3T3 Fibroblasts and Promotes Nuclei Accumulation of SAHF}

To evaluate whether T. cruzi infection is able to interfere with the cell proliferation capacity, we infected CFSE-labeled fibroblasts with trypomastigotes and 3 days post-infection, we analyzed cell proliferation by flow cytometry (48). We observed that the fluorescence intensity of T. cruzi-infected NIH-3T3 fibroblasts stayed at high level while non-infected NIH-3T3 fibroblasts had a rapid decrease of fluorescence intensity, indicating that infection inhibited the proliferation of fibroblasts (Figure 2A). In addition, by DAPI staining, we found that the nuclei of T. cruzi-infected fibroblasts acquired the characteristic morphology of senescent cells, by showing an enlarged size and several bright, punctate SAHF (Figure 2B, upper and lower right panels) (26). By contrast, non-infected fibroblasts displayed a more uniform DAPI staining pattern (Figure 2B, upper and lower left panels). These data suggest that T. cruzi infection induces a senescent-like phenotype and alters NIH-3T3 fibroblasts proliferative ability.

\section{T. cruzi Infection Imprints a Senescent- Like Phenotype in NIH-3T3 Fibroblasts}

Senescent cells are characterized by an increase in SA- $\beta$-gal activity $(27,28)$ and SASP $(29,30)$. To verify whether T. cruzi-infected NIH-3T3 fibroblasts have characteristics of cellular senescence, we first evaluated one of the hallmarks of cellular senescence, the soluble SA- $\beta$-gal activity, in cell lysates of T. cruzi-infected and non-infected fibroblasts. Our results showed that T. cruzi infection increased the activity of SA- $\beta$-gal measured at $\mathrm{pH} 6.0$ in fibroblasts (Figure 3A). Furthermore, to verify whether T. cruziinfected fibroblasts display SASP, we measured the levels of IL-6, IL- $1 \beta$, TNF- $\alpha$, and MCP- 1 as well as non-SASP-related cytokine IL-10 in the culture supernatants 3 days p.i. We found that T. cruzi-infected fibroblasts produced markedly more IL-6, IL-1 $\beta$, and TNF- $\alpha$, as well as MCP-1 when compared to non-infected cells (Figure 3B). Moreover, we did not observe differences in the production of non-SASP cytokine IL-10 by infected and non-infected fibroblasts (Figure 3C). Furthermore, we found that T. cruzi infection induced the release of NO by NIH-3T3 fibroblasts in the culture supernatants (Figure 3D). Taken together these results indicate that $T$. cruzi-infected fibroblasts present typical senescent cells secretion profile.

\section{Antioxidants Inhibit the Induction of SASP and Control Parasite Growth in T. cruzi-Infected NIH-3T3 Fibroblasts}

To investigate whether the induction of senescent-like phenotype is due to autocrinally/paracrinally action of soluble factors released by T. cruzi-infected fibroblasts, NIH-3T3 cells were infected with culture-derived T. cruzi trypomastigotes (multiplicity of infection 5:1) overnight. After washing out extracellular parasites, cultures 


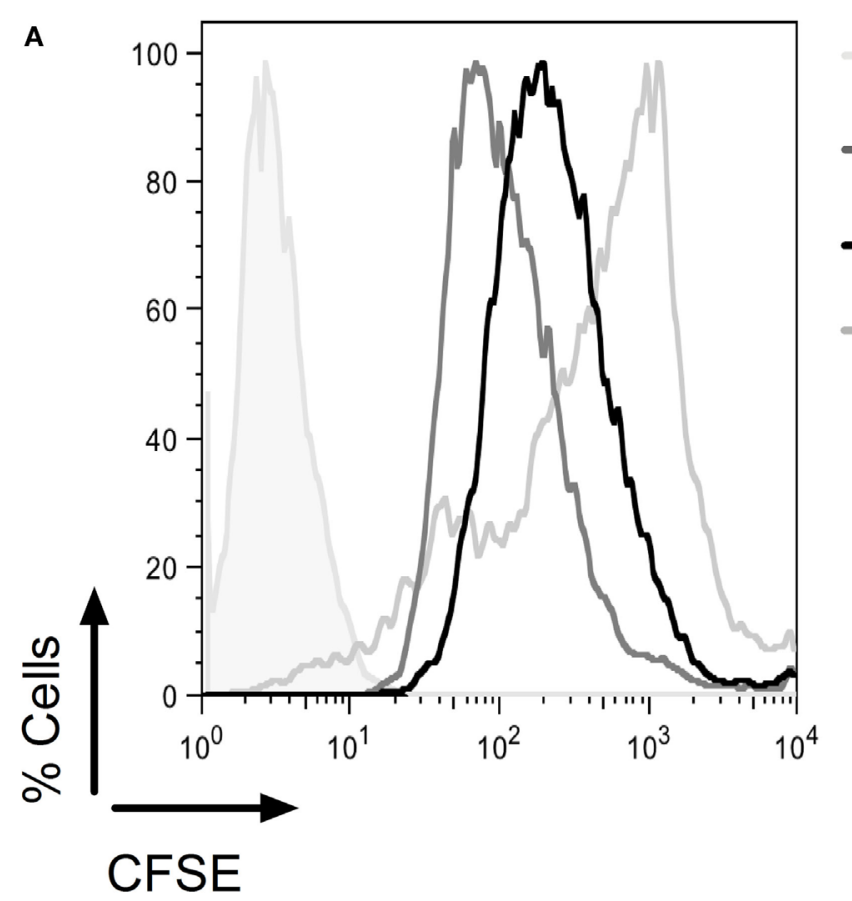

Ctrl (unlabeled)
$-\operatorname{Ctrl}(3 \mathrm{~d})$
- T. cruzi (3d)
- Ctrl (freshly labeled)

B

Ctrl

T. cruzi
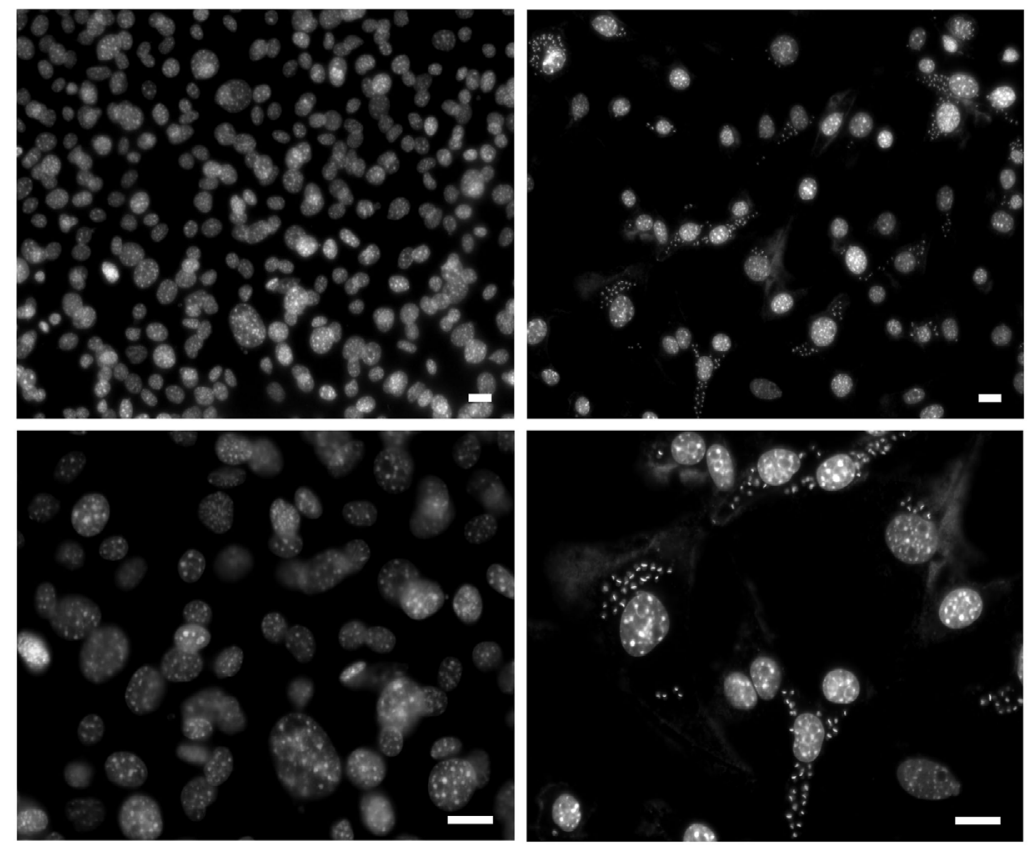

FIGURE 2 | Trypanosoma cruzi infection inhibits fibroblasts proliferation and induces an accumulation of senescence-associated heterochromatin foci (SAHF). $\mathrm{NIH}-3$ T3 fibroblasts were infected with culture-derived T. cruzi trypomastigotes (MOI 5:1) overnight followed by a washing step to eliminate extracellular parasites. (A) Assessment of cellular proliferative capacity in CFSE-labeled fibroblasts 3 days (3d) post-infection and before infection (Od) by flow cytometry. Fibroblasts were first gated based on FSC-A versus SSC-A parameters, and then CFSE staining was analyzed. (B) T. cruzi-infected and non-infected NIH-3T3 fibroblasts stained with DAPI (upper panels, 20x magnification) 3 days post-infection. Enlarged images of DAPI staining are shown in the lower panels (40x magnification). The fluorescence images were obtained and photographed from multiple fields, by using an Axioplan II microscope (Zeiss) and image pro-plus software version 7.0.1. Scale bars are equal to $20 \mu \mathrm{m}$. Data are representative of at least three independent experiments with similar results. Abbreviations: MOI, multiplicity of infection; Ctrl, control; CFSE, carboxyfluorsecein diacetate succinimidyl ester. 
A
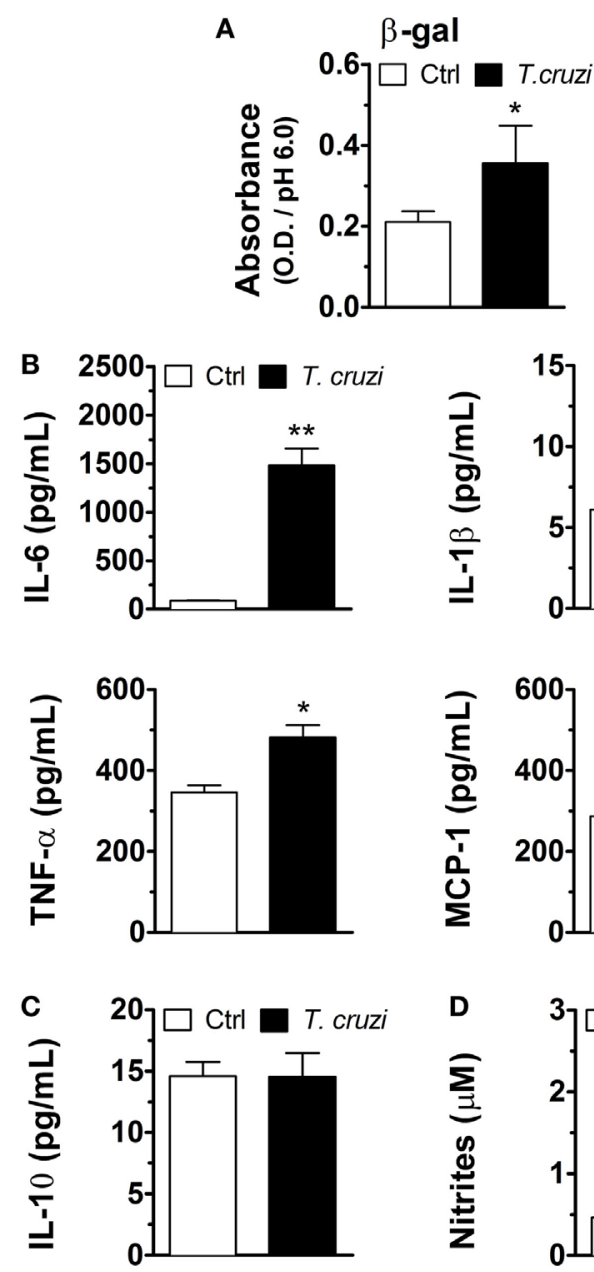
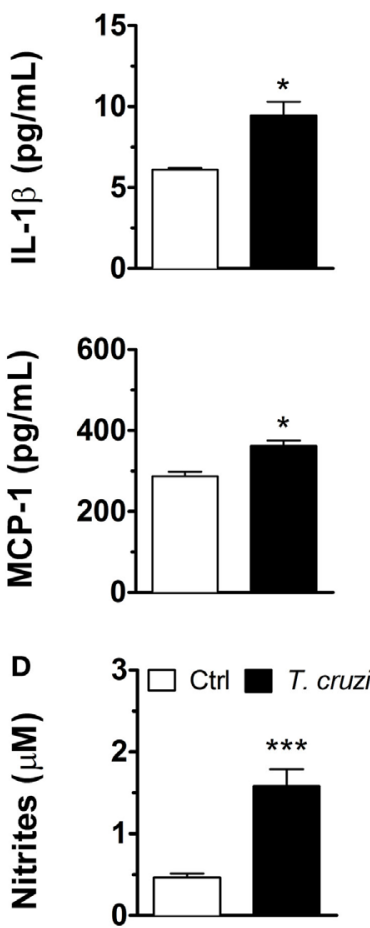

FIGURE 3 | Trypanosoma cruzi-infected NIH-3T3 fibroblasts have characteristics of cellular senescence. $\mathrm{NIH}-3 \mathrm{~T} 3$ fibroblasts were infected overnight with culture-derived T. cruzi trypomastigotes (MOI 5:1). (A) Evaluation of soluble SA- $\beta$-gal activity at $\mathrm{pH} 6.0$ in cell lysates of T. cruzi-infected and non-infected fibroblasts 3 days post-infection. (B,C) Measurement of senescence-associated secretory phenotype (SASP) cytokines IL-6, TNF- $\alpha$ and IL- $1 \beta$ and chemokine MCP-1, as well as SASP non-related IL-10, in the 3 days post-infection culture supernatants by ELISA. (D) Evaluation of nitric oxide release by T. cruzi-infected and non-infected fibroblasts in culture supernatants 3 days post-infection by Griess reaction. Data are presented as the mean \pm SE of at least six biological replicates and analyzed by (A) non-parametric Mann-Whitney test, and (B-D) unpaired, two-tailed Student's $t$-test, ${ }^{\star} p<0.05$; ${ }^{* \star} p<0.01$; ${ }^{\star \star \star} p<0.001$; NS, statistically not significant, $p>0.05$. Data are representative of at least three independent experiments with similar results. Abbreviations: $\mathrm{MOI}$, multiplicity of infection; Ctrl, control; SA- $\beta$-gal, senescence-associated $\beta$-galactosidase.

were treated with $50 \%$ supernatants from non-infected cultures (control) or T. cruzi-infected [control conditioned medium (Ctrl-CM) or T. cruzi CM (Tc-CM), respectively] plus $50 \%$ of fresh medium. After 3 days, the numbers of non-infected or T. cruzi-infected fibroblasts were quantified in the optical microscope. We found that the treatment with Ctrl-CM did not affect the numbers of fibroblasts in infected or non-infected cultures (Figure 4A). On the other hand, the treatment of non-infected

cultures with Tc-CM for 3 days triggered a great reduction in the overall numbers of cells in a similar manner to the cultures infected with T. cruzi in the absence of Tc-CM treatment (Figure 4B). Interestingly, the treatment of $T$. cruzi-infected cultures with Tc-CM induced an even higher reduction of cell number compared to the Tc-CM non-treated cultures infected with T. cruzi (Figure 4B), suggesting that soluble factor(s) released by T. cruziinfected fibroblasts control cellular proliferation and possible other senescence hallmarks in an autocrine/paracrine manner. One of the soluble factors potentially involved in the induction of senescence in infected fibroblasts are ROS, since their production has been implicated in DNA damage with a consequent control of cellular proliferation and senescence phenotype induction (49). We therefore assessed ROS accumulation after T. cruzi infection in NIH-3T3 fibroblasts using the fluorescent probe DCFH-DA. We observed an accumulation of ROS in infected fibroblasts starting $2 \mathrm{~h}$ p.i., and reaching a peak $72 \mathrm{~h}$ p.i. (Figure 4C). To determine whether the accumulation of ROS is critical for the induction of senescent-like phenotype by T. cruzi infection, we evaluated the soluble SA- $\beta$-gal activity and SASP cytokine IL- 6 in cell lysates and supernatants, respectively, of T. cruzi-infected and non-infected fibroblasts, in the presence or absence of ROS scavengers NAC, a thiol compound that increases the levels of reduced glutathione, and DFO, an iron chelator that inhibits radical production. Briefly, cells were treated with the probe DCFH-DA 20 min followed by T. cruzi infection with addition of NAC or DFO during infection period. We confirmed that the addition of both antioxidants reduced ROS generation (Figure S1 in Supplementary Material). The treatment with antioxidants NAC or DFO during T. cruzi infection remarkably reduced SA- $\beta$-gal activity (Figure 4D) as well as the secretion of the SASP cytokines IL-6 (Figure 4E) by NIH-3T3 fibroblasts. On the other hand, the treatment with antioxidants did not restore the cellular proliferative capacity (data not shown), but reduced the number of released parasites by fibroblasts (Figure 4F). Together, our data suggest that T. cruzi-induced ROS are one of the main inducers of senescent-like phenotype in NIH-3T3 fibroblasts, which support the intracellular growth of T. cruzi.

\section{DISCUSSION}

The establishment of T. cruzi infection and therefore Chagas disease occurs when the parasites are internalized by phagocytic cells that are recruited to the vector's bite sites. However, since these parasites have the ability to invade almost any cell type, even before reach immune cells, T. cruzi trypomastigotes may interact with nonimmune cells, such as epithelial cells and fibroblasts in host skin and mucosal surfaces $(11,18)$. Thus, the early events of parasite-host interaction may play a fundamental role in development of immune responses and consequently in the outcome of chronic infection.

Although the interaction between T. cruzi and phagocytic cells such as macrophages is well established in the literature, little is known about T. cruzi infection in non-immune cells. To gain a clearer understanding of parasite-host interactions at early stages of Chagas disease, we examined cellular aspects of the in vitro infection of NIH-3T3 fibroblasts by T. cruzi. Our data reveal that NIH-3T3 fibroblasts are susceptible to T. cruzi infection with an earlier release of trypomastigotes to the culture medium 


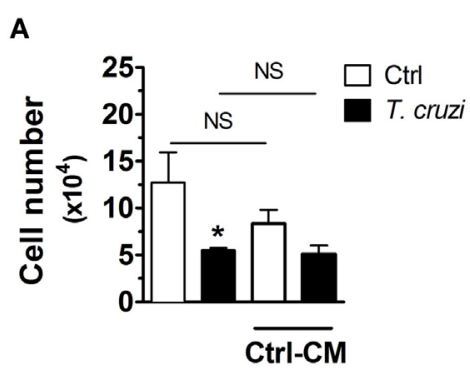

B

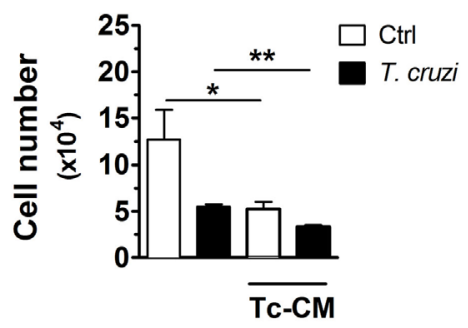

C

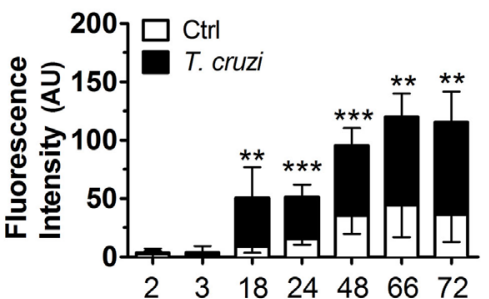

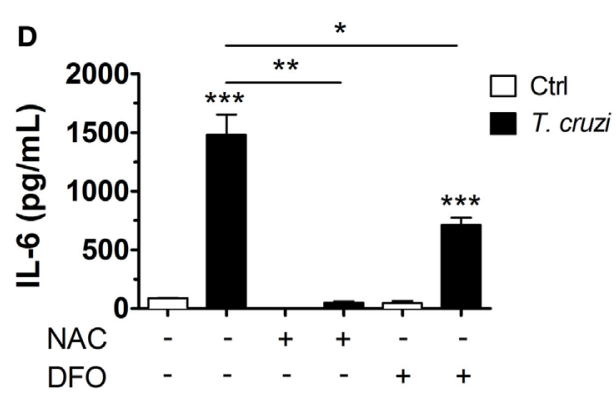

E

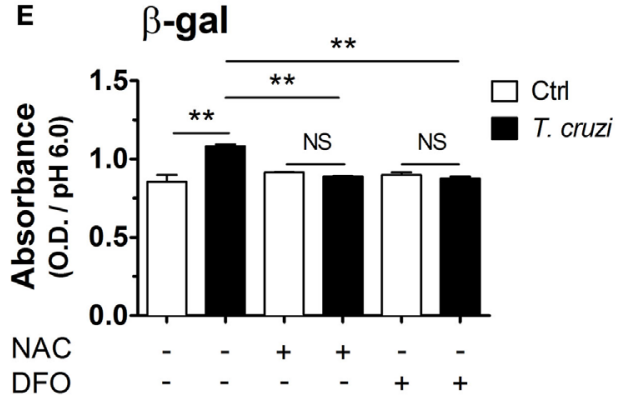

$F$

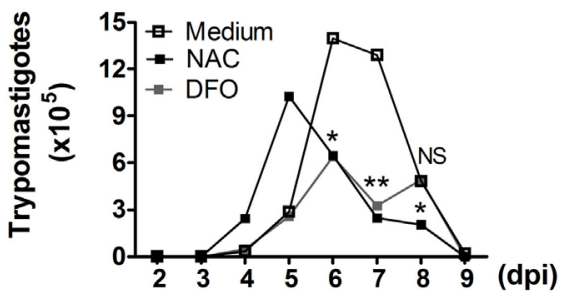

FIGURE 4 | Trypanosoma cruzi-induced ROS is a potent inducer of SASP in NIH-3T3 fibroblasts. NIH-3T3 fibroblasts were infected overnight with culture-derived T. cruzi trypomastigotes (MOI 5:1). After washing step to eliminate extracellular parasites, cultures were treated with (A) 50\% supernatants from non-infected or (B) T. cruzi-infected cultures (conditioned medium) plus $50 \%$ of fresh medium. After 3 days, the number of T. cruzi-infected or non-infected fibroblasts were quantified by optical microscopy. Dead cells were evaluated by Trypan blue exclusion assay. (C-E) NIH-3T3 fibroblasts were loaded with the probe DCFH-DA, washed and infected with T. cruzi concomitantly with addition of antioxidants NAC (20 mM) and DFO (40 $\mu$ M) during infection period (MOI 5:1). After overnight infection, cultures were washed to eliminate extracellular parasites and cultured for additional 3 days. (C) Assessment of ROS accumulation after T. cruzi infection in $\mathrm{NIH}-3 \mathrm{~T} 3$ fibroblasts by fluorescence. Results indicate arbitrary units of fluorescence. (D) Evaluation of IL-6 in culture supernatant by ELISA. (E) Evaluation of soluble SA- $\beta$-gal activity at pH 6.0 in cell lysates. (F) Assessment of extracellular parasitic load (trypomastigote forms) in culture supernatants over 10 days. Data are presented as the mean \pm SE of at least six biological replicates and analyzed by unpaired, two-tailed Student's $t$-test (C,D), and non-parametric Mann-Whitney test (E). For (A,B,F), data were log-transformed and analyzed by Student's $t$-test. ${ }^{*} p<0.05 ;{ }^{\star \star} p<0.01 ;{ }^{* \star *} p<0.001$; NS, statistically not significant, $p>0.05$. Data are representative of at least three independent experiments with similar results. Abbreviations: MOI, multiplicity of infection; Ctrl, control; ROS, reactive oxygen species; NAC, N-acetylcysteine; DFO, deferoxamine; DCFH-DA, dichloro-dihydro-fluorescein diacetate; h, hours; ROS, reactive oxygen species; SASP, senescenceassociated secretory phenotype; SA- $\beta$-gal, senescence-associated $\beta$-galactosidase.

(at the day 4) compared to macrophages (at the day 6) (50). In addition, we found a remarkable reduction in the overall numbers of cells in the infected compared to the non-infected fibroblasts, with equal numbers of dead (apoptotic) cells in both conditions, suggesting that T. cruzi infection may interfere with the cellular proliferative capacity of fibroblasts. In fact, regulating host cell cycle is one of the mechanisms used by many intracellular pathogens, including T. cruzi, to facilitate its replication and permanence within the organism (19-23). Furthermore, previous studies have suggested that T. cruzi infection impedes cell cycle progression in the host non-immune cells (22) and reprograms epithelial cells by regulating several genes involved in cellular defense, response to stress, and suppression of cell proliferation (11). In accordance, we found that T. cruzi infection alter NIH-3T3 fibroblasts phenotype and proliferative capacity, as verified by CFSE dilution assay.

Senescent cells do not proliferate, and are characterized by distinctive phenotypic alterations, including increased size and flattened morphology, enlarged and multinucleated nuclei $(27,51)$. Similarly, T. cruzi-infected NIH-3T3 fibroblasts acquired the characteristic senescent morphology showing enlarged and flattened cells with nuclei accumulation of SAHF, while non-infected fibroblasts displayed sharped morphology and a more uniform DAPI staining pattern. The induction of cellular senescence could provide an advantage or a disadvantage to the host. During homeostasis, the proliferative arrest avoids the development of cancer, since it prevents the propagation of damaged or stressed 
cells, which are in risk of neoplastic transformation $(52,53)$, for example. On the other hand, based on our in vitro studies, we believe that during Chagas disease, senescent fibroblasts, especially in the skin, become a long-term reservoir of parasites, which are released to infect resident and recruited cells. Besides the irreversible arrest of cell proliferation and the distinct heterochromatic structure $(25,26)$, senescent cells are characterized by an increased SA- $\beta$-gal activity due to the presence of more and bigger lysosomes $(27,51,54)$. In accordance, NIH-3T3 fibroblasts infected with T. cruzi showed increased SA- $\beta$-gal activity, indicating that T. cruzi infection induces senescent-like phenotype in NIH-3T3 fibroblasts. Although increased SA- $\beta$-gal activity is a hallmark of senescent cells, its role in senescence induction and/ or maintenance remains to be addressed.

All senescent cells are stably viable and continue to secrete large amounts of soluble factors, collectively named as SASP. SASP components are mainly growth factors, extracellular matrix remodeling enzymes, NO, chemokines, and proinflammatory cytokines, such as MCP-1, IL- 6 , TNF- $\alpha$, and IL-1 $\beta$ (29-31). The role of SASP is to reinforce the senescence arrest in an autocrine and/or paracrine manner (55) able to alter the tissue microenvironment by recruiting and interacting with immune system cells, promoting the recognition and clearance of senescent cells $(29,30)$. We found that T. cruzi-infected fibroblasts display SASP, with markedly higher production of NO, MCP-1, IL-6, IL-1 $\beta$, and TNF- $\alpha$ when compared to non-infected fibroblasts. Again, SASP can be beneficial or deleterious, depending on the biological context. In this sense, although this proinflammatory response could reflect defense mechanisms against the parasite, we cannot discard that SASP factors can be exploited by T. cruzi as a strategy for their survival and dissemination. Particularly, IL-1 $\beta$, IL-6, TNF- $\alpha$, and MCP- 1 are efficient in triggering inflammation and recruitment of neutrophils, macrophages, and other immune cells (56-60), which can be infected by this parasite and spread the disease, since immune cells are mobile. In fact, the strategy for dissemination by neutrophil attraction and infection has been reported for Leishmania infection (61-63). Another SASP factor, NO, is an important cytotoxic and cytostatic factor in cellmediated immune responses against many intracellular pathogens including Leishmania spp. and Toxoplasma gondii (64-67). However, its role in T. cruzi infection is controversial. Some studies support the role of NO in the control of T. cruzi infection $(68,69)$, while others demonstrate that NO is not required to eliminate these parasites $(70,71)$. In our model, although senescent infected fibroblasts produce NO, this factor seems not be important to eliminate intracellular T. cruzi. Moreover, the amount of NO released by $T$. cruzi-infected fibroblasts is very low when compared with macrophages $(72,73)$, and may not be sufficient to have a microbicidal effect on intracellular T. cruzi.

Cellular senescence occurs in culture and in vivo as a response to excessive extracellular or intracellular stress (74). A plethora of stresses can provoke cellular senescence, including dysfunction of mitochondria and oxidative stress (75). Notably, an important feature in the infection by $T$. cruzi is the oxidant stress response that is very relevant for the parasite's pathogenesis. Although the oxidative stress generated after T. cruzi infection is a hallmark of professional phagocytic cells, it has been also demonstrated that this response is generated in non-phagocytic cells by many mechanisms, including an increased release of mitochondrial free radicals in cardiomyocytes (76), and in infected mice (77), as well as SASP cytokines signaling such as TNF (9). In agreement with that, we found an accumulation of ROS in infected fibroblasts. Many pathways could trigger cellular stress response characterized by increased ROS generation in T. cruzi-infected fibroblasts, including SAPK/JNK pathway, as previously shown by our group in macrophages infected by Leishmania major (78). In addition, the treatment with the antioxidants NAC and DFO during T. cruzi infection remarkably reduced the secretion of the most prominent SASP cytokine IL-6, and SA- $\beta$-gal activity by NIH-3T3 fibroblasts. On the other hand, the treatment with antioxidants did not restore the proliferative capacity of fibroblasts, suggesting that other factors than ROS control different aspects of cellular senescence induction in T. cruzi-infected fibroblasts. Importantly, we found a reduction in the number of trypomastigotes released by fibroblasts treated with DFO or NAC, which suggests that the presence of ROS during T. cruzi infection favor the intracellular growth of these parasites. Our data agree with the identified role of ROS in intracellular survival/ growth of Leishmania and T. cruzi parasites $(50,78,79)$. Based on that, we hypothesize that in vivo treatment with antioxidants could control the parasitemia and perhaps, the spread of Chagas disease. Furthermore, we found that soluble factors released by T. cruzi-infected fibroblasts can control cellular proliferation and possible other senescence hallmarks in a paracrine manner in non-infected fibroblasts through CM experiments. However, we neither identify the exact factor(s) responsible for the cell arrest in infected fibroblasts nor the role of these soluble factors modulating the function of other cells such as epithelial cells, and resident and recruited immune cells. Besides their effects in fibroblasts, we hypothesize that SASP factors such as IL-6 and NO released by senescent cells can modulate the functions of neighborhood macrophages, dendritic cells (DCs), T cells as well as epithelial cells, and keratinocytes. In fact, it has been described that IL-6 induces epidermal cell proliferation and thickening of stratum corneum, increasing skin protection from infection (80), which is probably occurs during skin manifestations of Chagas disease.

In macrophages, IL- 6 promotes M2 polarization $(81,82)$ and blocks DCs maturation $(83,84)$. Similarly, NO suppresses DCs maturation as well as their capacity to activate naive T cells (85-87), inhibits proliferation and production of IFN- $\gamma$ by T cells (88), and promotes the differentiation of Treg cells (89). All these factors may favor T. cruzi survival and permanence in the host during acute phase of Chagas disease. Future studies using Tc-CM in macrophages and/or DCs cultures need to be performed to evaluate whether factors released by $T$. cruzi-induced senescent fibroblasts could modulate microbicidal function, antigen presentation, migration properties, and induction of senescence in these phagocytic immune cells.

In summary, our results provide new information regarding the early cellular responses to $T$. cruzi infection that may be relevant to the establishment of Chagas disease. We showed that fibroblasts are susceptible to T. cruzi infection and they are not able to control the initial parasite replication. Moreover, T. cruzi infection inhibits cellular proliferation and induces a senescent-like 
phenotype in fibroblasts, which may allow more time for T. cruzi to replicate and produce its intracellular nests. Thus, senescentlike fibroblasts act as a reservoir of T. cruzi at the initial stages of infection. The exact role of the senescence in the control or progression of Chagas disease will be further investigated, thus contributing to our better understanding of this complex chronic disease. Our findings provide new insight into the mechanisms by which intracellular T. cruzi infection influences the host cells, leading to pathogenicity; and could be important to define new therapeutic interventions to treat Chagas disease.

\section{AUTHOR CONTRIBUTIONS}

KG-P, DN, GD, and AF designed experiments and analyzed data. KG-P, DN, and AC-F performed experiments. GD and AF supervised the experiments. CF-d-L and AM contributed reagents/ analysis tools. ML contributed reagents/analysis tools and to the critical revision of the manuscript. GD conceived the research. AF wrote the manuscript. All authors read and approved the submitted version of the manuscript.

\section{REFERENCES}

1. Bern C, Kjos S, Yabsley MJ, Montgomery SP. Trypanosoma cruzi and Chagas' disease in the United States. Clin Microbiol Rev (2011) 24(4):655-81. doi:10.1128/ CMR.00005-11

2. Bern C, Montgomery SP. An estimate of the burden of Chagas disease in the United States. Clin Infect Dis (2009) 49(5):e52-4. doi:10.1086/605091

3. Montgomery SP, Starr MC, Cantey PT, Edwards MS, Meymandi SK. Neglected parasitic infections in the United States: Chagas disease. Am J Trop Med Hyg (2014) 90(5):814-8. doi:10.4269/ajtmh.13-0726

4. Soares VA, Marsden PD. [Penetration of Trypanosoma cruzi through triatomine bite sites]. Rev Soc Bras Med Trop (1986) 19(3):165-6. doi:10.1590/ S0037-86821986000300007

5. Costa CH, Costa MT, Weber JN, Gilks GF, Castro C, Marsden PD. Skin reactions to bug bites as a result of xenodiagnosis. Trans $\mathrm{R}$ Soc Trop Med Hyg (1981) 75(3):405-8. doi:10.1016/0035-9203(81)90105-X

6. Maeda FY, Cortez C, Alves RM, Yoshida N. Mammalian cell invasion by closely related Trypanosoma species T. dionisii and T. cruzi. Acta Trop (2012) 121(2):141-7. doi:10.1016/j.actatropica.2011.10.017

7. de Souza W, de Carvalho TM, Barrias ES. Review on Trypanosoma cruzi: host cell interaction. Int J Cell Biol (2010) 2010:295394. doi:10.1155/2010/295394

8. Caradonna KL, Burleigh BA. Mechanisms of host cell invasion by Trypanosoma cruzi. Adv Parasitol (2011) 76:33-61. doi:10.1016/B978-0-12-385895-5.00002-5

9. Epting CL, Coates BM, Engman DM. Molecular mechanisms of host cell invasion by Trypanosoma cruzi. Exp Parasitol (2010) 126(3):283-91. doi:10.1016/j. exppara.2010.06.023

10. Martello LA, Wadgaonkar R, Gupta R, Machado FS, Walsh MG, Mascareno E, et al. Characterization of Trypanosoma cruzi infectivity, proliferation, and cytokine patterns in gut and pancreatic epithelial cells maintained in vitro. Parasitol Res (2013) 112(12):4177-83. doi:10.1007/s00436-013-3609-7

11. Chiribao ML, Libisch G, Parodi-Talice A, Robello C. Early Trypanosoma cruzi infection reprograms human epithelial cells. Biomed Res Int (2014) 2014: 439501. doi:10.1155/2014/439501

12. Houston-Ludlam GA, Belew AT, El-Sayed NM. Comparative transcriptome profiling of human foreskin fibroblasts infected with the Sylvio and Y strains of Trypanosoma cruzi. PLoS One (2016) 11(8):e0159197. doi:10.1371/journal. pone.0159197

13. El-Sayed NM, Myler PJ, Bartholomeu DC, Nilsson D, Aggarwal G, Tran AN, et al. The genome sequence of Trypanosoma cruzi, etiologic agent of Chagas disease. Science (2005) 309(5733):409-15. doi:10.1126/science.1112631

14. Atwood JA III, Weatherly DB, Minning TA, Bundy B, Cavola C, Opperdoes FR, et al. The Trypanosoma cruzi proteome. Science (2005) 309(5733):473-6. doi:10.1126/science.1110289

\section{ACKNOWLEDGMENTS}

We thank Jorgete L. Oliveira and Lindomar M. da Silva (UFRJ) for technical assistance and Dr. Leonardo Augusto Karam Teixeira (INCA) for helpful discussions.

\section{FUNDING}

This work was supported by the Brazilian National Research Council (Conselho Nacional de Desenvolvimento Científico e Tecnológico, CNPq), The Rio de Janeiro State Science Foundation (Fundação Carlos Chagas Filho de Amparo à Pesquisa do Estado do Rio de Janeiro, FAPERJ), and the National Institutes of Science and Technology (INCT-INPeTAm/CNPq/MCT).

\section{SUPPLEMENTARY MATERIAL}

The Supplementary Material for this article can be found online at https://www.frontiersin.org/articles/10.3389/fimmu.2018.01569/ full\#supplementary-material.

15. Schenkman S, Andrews NW, Nussenzweig V, Robbins ES. Trypanosoma cruzi invade a mammalian epithelial cell in a polarized manner. Cell (1988) 55(1):157-65. doi:10.1016/0092-8674(88)90018-9

16. Coelho LL, Pereira IR, Pereira MCS, Mesquita L, Lannes-Vieira J, Adesse D, et al. Trypanosoma cruzi activates mouse cardiac fibroblasts in vitro leading to fibroblast-myofibroblast transition and increase in expression of extracellular matrix proteins. Parasit Vectors (2018) 11(1):72. doi:10.1186/s13071018-2614-1

17. Mortara RA, Andreoli WK, Taniwaki NN, Fernandes AB, Silva CV, Fernandes MC, et al. Mammalian cell invasion and intracellular trafficking by Trypanosoma cruzi infective forms. An Acad Bras Cienc (2005) 77(1):77-94. doi:10.1590/S0001-37652005000100006

18. Fernandez-Aguilar S, Lambot MA, Torrico F, Alonso-Vega C, Cordoba M, Suarez E, et al. [Placental lesions in human Trypanosoma cruzi infection]. Rev Soc Bras Med Trop (2005) 38(Suppl 2):84-6.

19. Zhao RY, Elder RT. Viral infections and cell cycle G2/M regulation. Cell Res (2005) 15(3):143-9. doi:10.1038/sj.cr.7290279

20. Dobbelaere DA, Kuenzi P. The strategies of the Theileria parasite: a new twist in host-pathogen interactions. Curr Opin Immunol (2004) 16(4):524-30. doi:10.1016/j.coi.2004.05.009

21. Molestina RE, El-Guendy N, Sinai AP. Infection with Toxoplasma gondii results in dysregulation of the host cell cycle. Cell Microbiol (2008) 10(5):1153-65. doi:10.1111/j.1462-5822.2008.01117.x

22. Costales JA, Daily JP, Burleigh BA. Cytokine-dependent and-independent gene expression changes and cell cycle block revealed in Trypanosoma cruzi-infected host cells by comparative mRNA profiling. BMC Genomics (2009) 10:252. doi:10.1186/1471-2164-10-252

23. Dvorak JA, Crane MS. Vertebrate cell cycle modulates infection by protozoan parasites. Science (1981) 214(4524):1034-6. doi:10.1126/science.7029713

24. Campisi J, d'Adda di Fagagna F. Cellular senescence: when bad things happen to good cells. Nat Rev Mol Cell Biol (2007) 8(9):729-40. doi:10.1038/nrm2233

25. Blagosklonny MV. Cell senescence and hypermitogenic arrest. EMBO Rep (2003) 4(4):358-62. doi:10.1038/sj.embor.embor806

26. Narita M, Nunez S, Heard E, Narita M, Lin AW, Hearn SA, et al. Rb-mediated heterochromatin formation and silencing of E2F target genes during cellular senescence. Cell (2003) 113(6):703-16. doi:10.1016/S0092-8674(03) 00401-X

27. Dimri GP, Lee X, Basile G, Acosta M, Scott G, Roskelley C, et al. A biomarker that identifies senescent human cells in culture and in aging skin in vivo. Proc Natl Acad Sci U S A (1995) 92(20):9363-7. doi:10.1073/pnas.92.20.9363

28. Lee BY, Han JA, Im JS, Morrone A, Johung K, Goodwin EC, et al. Senescenceassociated beta-galactosidase is lysosomal beta-galactosidase. Aging Cell (2006) 5(2):187-95. doi:10.1111/j.1474-9726.2006.00199.x 
29. Coppe JP, Patil CK, Rodier F, Sun Y, Munoz DP, Goldstein J, et al. Senescenceassociated secretory phenotypes reveal cell-nonautonomous functions of oncogenic RAS and the p53 tumor suppressor. PLoS Biol (2008) 6(12):e301. doi:10.1371/journal.pbio.0060301

30. Rodier F, Coppe JP, Patil CK, Hoeijmakers WA, Munoz DP, Raza SR, et al. Persistent DNA damage signalling triggers senescence-associated inflammatory cytokine secretion. Nat Cell Biol (2009) 11(8):973-9. doi:10.1038/ncb1909

31. Freund A, Orjalo AV, Desprez PY, Campisi J. Inflammatory networks during cellular senescence: causes and consequences. Trends Mol Med (2010) 16(5): 238-46. doi:10.1016/j.molmed.2010.03.003

32. de Magalhaes JP. From cells to ageing: a review of models and mechanisms of cellular senescence and their impact on human ageing. Exp Cell Res (2004) 300(1):1-10. doi:10.1016/j.yexcr.2004.07.006

33. Munoz-Espin D, Canamero M, Maraver A, Gomez-Lopez G, Contreras J, Murillo-Cuesta S, et al. Programmed cell senescence during mammalian embryonic development. Cell (2013) 155(5):1104-18. doi:10.1016/j.cell.2013. 10.019

34. Krtolica A, Parrinello S, Lockett S, Desprez PY, Campisi J. Senescent fibroblasts promote epithelial cell growth and tumorigenesis: a link between cancer and aging. Proc Natl Acad Sci U S A (2001) 98(21):12072-7. doi:10.1073/pnas. 211053698

35. Mooi WJ, Peeper DS. Oncogene-induced cell senescence - halting on the road to cancer. N Engl J Med (2006) 355(10):1037-46. doi:10.1056/NEJMra062285

36. Shivshankar P, Boyd AR, Le Saux CJ, Yeh IT, Orihuela CJ. Cellular senescence increases expression of bacterial ligands in the lungs and is positively correlated with increased susceptibility to pneumococcal pneumonia. Aging Cell (2011) 10(5):798-806. doi:10.1111/j.1474-9726.2011.00720.x

37. Kim JA, Seong RK, Shin OS. Enhanced viral replication by cellular replicative senescence. Immune Netw (2016) 16(5):286-95. doi:10.4110/in.2016.16.5.286

38. Baz-Martinez M, Da Silva-Alvarez S, Rodriguez E, Guerra J, El Motiam A, Vidal A, et al. Cell senescence is an antiviral defense mechanism. Sci Rep (2016) 6:37007. doi:10.1038/srep37007

39. Papagno L, Spina CA, Marchant A, Salio M, Rufer N, Little S, et al. Immune activation and CD8+ T-cell differentiation towards senescence in HIV-1 infection. PLoS Biol (2004) 2(2):E20. doi:10.1371/journal.pbio.0020020

40. Albareda MC, Olivera GC, Laucella SA, Alvarez MG, Fernandez ER, Lococo B, et al. Chronic human infection with Trypanosoma cruzi drives CD4+ T cells to immune senescence. J Immunol (2009) 183(6):4103-8. doi:10.4049/jimmunol. 0900852

41. Albareda MC, Olivera GC, De Rissio AM, Postan M. Assessment of CD8(+) $\mathrm{T}$ cell differentiation in Trypanosoma cruzi-infected children. Am J Trop Med Hyg (2010) 82(5):861-4. doi:10.4269/ajtmh.2010.09-0604

42. Ba X, Gupta S, Davidson M, Garg NJ. Trypanosoma cruzi induces the reactive oxygen species-PARP-1-RelA pathway for up-regulation of cytokine expression in cardiomyocytes. J Biol Chem (2010) 285(15):11596-606. doi:10.1074/ jbc.M109.076984

43. Andrews NW, Colli W. Adhesion and interiorization of Trypanosoma cruzi in mammalian cells. J Protozool (1982) 29(2):264-9. doi:10.1111/j.15507408.1982.tb04024.x

44. Kwon NS, Nathan CF, Stuehr DJ. Reduced biopterin as a cofactor in the generation of nitrogen oxides by murine macrophages. J Biol Chem (1989) 264(34):20496-501.

45. Sundaresan M, Yu ZX, Ferrans VJ, Irani K, Finkel T. Requirement for generation of $\mathrm{H} 2 \mathrm{O} 2$ for platelet-derived growth factor signal transduction. Science (1995) 270(5234):296-9. doi:10.1126/science.270.5234.296

46. Contreras VT, Navarro MC, De Lima AR, Arteaga R, Duran F, Askue J, et al. Production of amastigotes from metacyclic trypomastigotes of Trypanosoma cruzi. Mem Inst Oswaldo Cruz (2002) 97(8):1213-20. doi:10.1590/S007402762002000800025

47. Tomlinson S, Vandekerckhove F, Frevert U, Nussenzweig V. The induction of Trypanosoma cruzi trypomastigote to amastigote transformation by low $\mathrm{pH}$. Parasitology (1995) 110(Pt 5):547-54. doi:10.1017/S0031182000065264

48. Hawkins ED, Hommel M, Turner ML, Battye FL, Markham JF, Hodgkin PD. Measuring lymphocyte proliferation, survival and differentiation using CFSE time-series data. Nat Protoc (2007) 2(9):2057-67. doi:10.1038/nprot. 2007.297

49. Mates JM, Segura JA, Alonso FJ, Marquez J. Intracellular redox status and oxidative stress: implications for cell proliferation, apoptosis, and carcinogenesis. Arch Toxicol (2008) 82(5):273-99. doi:10.1007/s00204-008-0304-z
50. Paiva CN, Feijo DF, Dutra FF, Carneiro VC, Freitas GB, Alves LS, et al. Oxidative stress fuels Trypanosoma cruzi infection in mice. J Clin Invest (2012) 122(7):2531-42. doi:10.1172/JCI58525

51. Collado M, Serrano M. The power and the promise of oncogene-induced senescence markers. Nat Rev Cancer (2006) 6(6):472-6. doi:10.1038/nrc1884

52. Campisi J. Cellular senescence as a tumor-suppressor mechanism. Trends Cell Biol (2001) 11(11):S27-31. doi:10.1016/S0962-8924(01)82148-6

53. Prieur A, Peeper DS. Cellular senescence in vivo: a barrier to tumorigenesis. Curr Opin Cell Biol (2008) 20(2):150-5. doi:10.1016/j.ceb.2008.01.007

54. Munoz-Espin D, Serrano M. Cellular senescence: from physiology to pathology. Nat Rev Mol Cell Biol (2014) 15(7):482-96. doi:10.1038/nrm3823

55. Perez-Mancera PA, Young AR, Narita M. Inside and out: the activities of senescence in cancer. Nat Rev Cancer (2014) 14(8):547-58. doi:10.1038/nrc3773

56. Rider P, Carmi Y, Guttman O, Braiman A, Cohen I, Voronov E, et al. IL-1alpha and IL-1beta recruit different myeloid cells and promote different stages of sterile inflammation. J Immunol (2011) 187(9):4835-43. doi:10.4049/jimmunol.1102048

57. Fielding CA, McLoughlin RM, McLeod L, Colmont CS, Najdovska M, Grail D, et al. IL-6 regulates neutrophil trafficking during acute inflammation via STAT3. J Immunol (2008) 181(3):2189-95. doi:10.4049/jimmunol.181.3.2189

58. Charmoy M, Hurrell BP, Romano A, Lee SH, Ribeiro-Gomes F, Riteau N, et al. The Nlrp3 inflammasome, IL-1beta, and neutrophil recruitment are required for susceptibility to a nonhealing strain of Leishmania major in C57BL/6 mice. Eur J Immunol (2016) 46(4):897-911. doi:10.1002/eji.201546015

59. Fielding CA, McLoughlin RM, Colmont CS, Kovaleva M, Harris DA, RoseJohn S, et al. Viral IL-6 blocks neutrophil infiltration during acute inflammation. J Immunol (2005) 175(6):4024-9. doi:10.4049/jimmunol.175.6.4024

60. Griffin GK, Newton G, Tarrio ML, Bu DX, Maganto-Garcia E, Azcutia V, et al. IL-17 and TNF-alpha sustain neutrophil recruitment during inflammation through synergistic effects on endothelial activation. JImmunol (2012) 188(12):6287-99. doi:10.4049/jimmunol.1200385

61. van Zandbergen G, Hermann N, Laufs H, Solbach W, Laskay T. Leishmania promastigotes release a granulocyte chemotactic factor and induce interleukin- 8 release but inhibit gamma interferon-inducible protein 10 production by neutrophil granulocytes. Infect Immun (2002) 70(8):4177-84. doi:10.1128/ IAI.70.8.4177-4184.2002

62. Ribeiro-Gomes FL, Sacks D. The influence of early neutrophil-Leishmania interactions on the host immune response to infection. Front Cell Infect Microbiol (2012) 2:59. doi:10.3389/fcimb.2012.00059

63. Laskay T, van Zandbergen G, Solbach W. Neutrophil granulocytes as host cells and transport vehicles for intracellular pathogens: apoptosis as infectionpromoting factor. Immunobiology (2008) 213(3-4):183-91. doi:10.1016/j. imbio.2007.11.010

64. Adams LB, Hibbs JB Jr, Taintor RR, Krahenbuhl JL. Microbiostatic effect of murine-activated macrophages for Toxoplasma gondii. Role for synthesis of inorganic nitrogen oxides from L-arginine. J Immunol (1990) 144(7):2725-9.

65. Green SJ, Meltzer MS, Hibbs JB Jr, Nacy CA. Activated macrophages destroy intracellular Leishmania major amastigotes by an L-arginine-dependent killing mechanism. J Immunol (1990) 144(1):278-83.

66. Khan IA, Schwartzman JD, Matsuura T, Kasper LH. A dichotomous role for nitric oxide during acute Toxoplasma gondii infection in mice. Proc Natl Acad Sci U S A (1997) 94(25):13955-60. doi:10.1073/pnas.94.25.13955

67. Liew FY, Millott S, Parkinson C, Palmer RM, Moncada S. Macrophage killing of Leishmania parasite in vivo is mediated by nitric oxide from L-arginine. J Immunol (1990) 144(12):4794-7.

68. Gazzinelli RT, Oswald IP, Hieny S, James SL, Sher A. The microbicidal activity of interferon-gamma-treated macrophages against Trypanosoma cruzi involves an L-arginine-dependent, nitrogen oxide-mediated mechanism inhibitable by interleukin-10 and transforming growth factor-beta. Eur J Immunol (1992) 22(10):2501-6. doi:10.1002/eji.1830221006

69. Holscher C, Kohler G, Muller U, Mossmann H, Schaub GA, Brombacher F. Defective nitric oxide effector functions lead to extreme susceptibility of Trypanosoma cruzi-infected mice deficient in gamma interferon receptor or inducible nitric oxide synthase. Infect Immun (1998) 66(3):1208-15.

70. Cummings KL, Tarleton RL. Inducible nitric oxide synthase is not essential for control of Trypanosoma cruzi infection in mice. Infect Immun (2004) 72(7):4081-9. doi:10.1128/IAI.72.7.4081-4089.2004

71. Saeftel M, Fleischer B, Hoerauf A. Stage-dependent role of nitric oxide in control of Trypanosoma cruzi infection. Infect Immun (2001) 69(4):2252-9. doi:10.1128/IAI.69.4.2252-2259.2001 
72. Vespa GN, Cunha FQ, Silva JS. Nitric oxide is involved in control of Trypanosoma cruzi-induced parasitemia and directly kills the parasite in vitro. Infect Immun (1994) 62(11):5177-82.

73. Cabral-Piccin MP, Guillermo LV, Vellozo NS, Filardy AA, Pereira-Marques ST, Rigoni TS, et al. Apoptotic CD8 T-lymphocytes disable macrophage-mediated immunity to Trypanosoma cruzi infection. Cell Death Dis (2016) 7:e2232. doi:10.1038/cddis. 2016.135

74. Campisi J. Aging, cellular senescence, and cancer. Annu Rev Physiol (2013) 75:685-705. doi:10.1146/annurev-physiol-030212-183653

75. Balaban RS, Nemoto S, Finkel T. Mitochondria, oxidants, and aging. Cell (2005) 120(4):483-95. doi:10.1016/j.cell.2005.02.001

76. Wen JJ, Vyatkina G, Garg N. Oxidative damage during chagasic cardiomyopathy development: role of mitochondrial oxidant release and inefficient antioxidant defense. Free Radic Biol Med (2004) 37(11):1821-33. doi:10.1016/j. freeradbiomed.2004.08.018

77. Wen JJ, Dhiman M, Whorton EB, Garg NJ. Tissue-specific oxidative imbalance and mitochondrial dysfunction during Trypanosoma cruzi infection in mice. Microbes Infect (2008) 10(10-11):1201-9. doi:10.1016/j.micinf.2008. 06.013

78. Filardy AA, Costa-da-Silva AC, Koeller CM, Guimaraes-Pinto K, RibeiroGomes FL, Lopes MF, et al. Infection with Leishmania major induces a cellular stress response in macrophages. PLoS One (2014) 9(1):e85715. doi:10.1371/ journal.pone.0085715

79. Mittra B, Cortez M, Haydock A, Ramasamy G, Myler PJ, Andrews NW. Iron uptake controls the generation of Leishmania infective forms through regulation of ROS levels. J Exp Med (2013) 210(2):401-16. doi:10.1084/jem. 20121368

80. Turksen K, Kupper T, Degenstein L, Williams I, Fuchs E. Interleukin 6: insights to its function in skin by overexpression in transgenic mice. Proc Natl Acad Sci US A (1992) 89(11):5068-72. doi:10.1073/pnas.89.11.5068

81. Mauer J, Chaurasia B, Goldau J, Vogt MC, Ruud J, Nguyen KD, et al. Signaling by IL-6 promotes alternative activation of macrophages to limit endotoxemia and obesity-associated resistance to insulin. Nat Immunol (2014) 15(5):423-30. doi:10.1038/ni.2865

82. Sanmarco LM, Ponce NE, Visconti LM, Eberhardt N, Theumer MG, Minguez AR, et al. IL- 6 promotes M2 macrophage polarization by modulating purinergic signaling and regulates the lethal release of nitric oxide during
Trypanosoma cruzi infection. Biochim Biophys Acta (2017) 1863(4):857-69. doi:10.1016/j.bbadis.2017.01.006

83. Hegde S, Pahne J, Smola-Hess S. Novel immunosuppressive properties of interleukin- 6 in dendritic cells: inhibition of NF-kappaB binding activity and CCR7 expression. FASEB J (2004) 18(12):1439-41. doi:10.1096/fj.03-0969fje

84. Park SJ, Nakagawa T, Kitamura H, Atsumi T, Kamon H, Sawa S, et al. IL-6 regulates in vivo dendritic cell differentiation through STAT3 activation. J Immunol (2004) 173(6):3844-54. doi:10.4049/jimmunol.173.6.3844

85. Corinti S, Pastore S, Mascia F, Girolomoni G. Regulatory role of nitric oxide on monocyte-derived dendritic cell functions. J Interferon Cytokine Res (2003) 23(8):423-31. doi:10.1089/107999003322277838

86. Wong SH, Santambrogio L, Strominger JL. Caspases and nitric oxide broadly regulate dendritic cell maturation and surface expression of class II MHC proteins. Proc Natl Acad Sci U S A (2004) 101(51):17783-8. doi:10.1073/pnas. 0408229102

87. Si C, Zhang R, Wu T, Lu G, Hu Y, Zhang H, et al. Dendritic cell-derived nitric oxide inhibits the differentiation of effector dendritic cells. Oncotarget (2016) 7(46):74834-45. doi:10.18632/oncotarget.11361

88. Xiong H, Kawamura I, Nishibori T, Mitsuyama M. Suppression of IFN-gamma production from Listeria monocytogenes-specific T cells by endogenously produced nitric oxide. Cell Immunol (1996) 172(1):118-25. doi:10.1006/cimm. 1996.0222

89. Niedbala W, Cai B, Liew FY. Role of nitric oxide in the regulation of T cell functions. Ann Rheum Dis (2006) 65(Suppl 3):iii37-40. doi:10.1136/ard. 2006.058446

Conflict of Interest Statement: The authors declare that the research was conducted in the absence of any commercial or financial relationships that could be construed as a potential conflict of interest.

Copyright (C) 2018 Guimarães-Pinto, Nascimento, Corrêa-Ferreira, Morrot, Freire-deLima, Lopes, DosReis and Filardy. This is an open-access article distributed under the terms of the Creative Commons Attribution License (CC BY). The use, distribution or reproduction in other forums is permitted, provided the original author(s) and the copyright owner(s) are credited and that the original publication in this journal is cited, in accordance with accepted academic practice. No use, distribution or reproduction is permitted which does not comply with these terms. 